\title{
A construção do papel do empreendedor social: mundos possíveis, discurso e o espírito do capitalismo ${ }^{1}$
}

\author{
Vander Casaqui
}

Resumo: Este trabalho, derivado de pesquisa de pós-doutoramento ${ }^{2}$, trata do tema do empreendedorismo social, tendo como objeto os discursos, extraídos da mídia digital, que caracterizam e conceituam a atuação dos empreendedores sociais. O objetivo é analisar os significados atribuídos ao empreendedor social, compreendido como agente que se ajusta ao novo espírito do capitalismo (BOLTANSKI; CHIAPELLO, 2009), ao incorporar o papel social (DAHRENDORF, 2012) de transformador dos cenários de crise, e simultaneamente configurar uma resposta ao desmonte do Estado social - o que fica evidente no contexto português. O percurso teórico-metodológico trata dos paradoxos conceituais que envolvem o empreendedorismo social; da lógica empreendedora que atravessa o imaginário do capitalismo contemporâneo; da noção de discurso social proposta por Angenot; e da abordagem multidimensional da análise de discurso por Fairclough.

Palavras-chave: empreendedorismo social; análise de discurso; espírito do capitalismo; mundos possíveis.

Abstract: Construction of the social entrepreneur's role: possible worlds, discourse and the spirit of capitalism - This paper derives from a post-doctoral research which deals with the theme of social entrepreneurship, having as object the discourses, extracted from digital media, which characterize and conceptualize the work of social entrepreneurs. The aim is to analyze the meanings attributed to social entrepreneur, understood as an agent that adjusts to the new spirit of capitalism (Boltanski and Chiapello) by incorporating the social role (Dahrendorf) of transforming crisis scenarios, and simultaneously setting a response to the dismantling of the Welfare State - which is evident in the portuguese context. The theoretical-methodological approach deals with the conceptual paradoxes involving social entrepreneurship; entrepreneurial logic that crosses the imaginary of contemporary capitalism; the notion of social discourse proposed by Angenot; and the multidimensional approach to discourse analysis by Fairclough.

Keywords: social entrepreneurship; discourse analysis; spirit of capitalism; possible worlds.

1 Versão modificada de artigo apresentado no XI Congresso da Lusocom (Federação das Associações Lusófonas de Ciências da Comunicação), realizado em Pontevedra - Espanha, Universidade deVigo, em 11 e 12 de abril de 2014.

2 Pesquisa financiada com bolsa Capes, Brasil, no primeiro semestre de 2013. Processo ${ }^{\circ}$ BEX 10542-12-4. 


\section{Introdução}

Nesta pesquisa, o tema do empreendedorismo social é desenvolvido por meio da análise de sua dimensão comunicacional, em diálogo com as lógicas sociais que caracterizam o contexto da produção de linguagem. A atividade do empreendedor social é revestida de significados, sempre atualizados pelas vozes dos agentes que correspondem ao seu campo (BOURDIEU, 2009), e para além dele, na circulação dos discursos no cenário social mais amplo.

Esses discursos, que elaboram mundos possíveis (LAZZARATO, 2006), estão presentes nos planos da Comissão Europeia para o período de 2014-2020; nos materiais produzidos por organizações globais como a Ashoka; bem como nos discursos da cena de empreendedorismo social portuguesa, estimulada por institucionalidades como o Instituto de Empreendedorismo Social (IES) e o Banco da Inovação Social (BIS), dentre outras. A abordagem de Fairclough (2001) é a perspectiva de análise aplicada a este estudo do empreendedorismo social.

Fairclough (ibid., p. 27-28) propõe uma aplicação da análise discursiva à investigação das mudanças sociais, das transformações dos métodos de produção em perspectiva histórica, que demandam outras atribuições e significados em relação aos trabalhadores: "descrever tais mudanças como 'culturais' não é apenas retórica: o objetivo é estabelecer novos valores culturais, operários que são 'empreendedores', automotivados (...), autodirecionados" (p. 26). Fairclough defende que as mudanças nas organizações e na cultura "são, de modo significativo, mudanças nas práticas discursivas" (ibid.). São quatro as dimensões previstas nessa abordagem, com seus respectivos métodos:

- Um método para análise multidimensional, que possibilita a avaliação entre mudanças discursivas e sociais, entre propriedades dos textos e propriedades da esfera da prática social, apreensíveis por sua configuração discursiva;

- Um método de análise multifuncional, a partir de uma concepção de discurso que contemple a relação entre as áreas do conhecimento (incluindo crenças e o senso comum), das relações sociais e das identidades - nessa concepção, "os textos simultaneamente representam a realidade, ordenam as relações sociais e estabelecem identidades" (ibid., p. 27);

- Um método de análise histórica, ou seja, a observação, através da análise de discurso, da construção de articulações textuais com outros textos (abordagem intertextual), e da constituição de ordens de discurso (no sentido foucaultiano), que considera as relações entre práticas discursivas e suas regulações, limitações, nas direções da mudança social a partir de instituições particulares ou da sociedade em sentido amplo; 
- Um método de análise crítica, uma vez que "as relações entre a mudança discursiva, social e cultural não são transparentes para as pessoas envolvidas" (ibid., p. 28). A desconstrução dos discursos, ao se evidenciar as conexões, causas, apagamentos e implícitos em suas formações, é uma maneira de intervenção no processo de mudança social, na visão de Fairclough.

Angenot (2010, p. 23) desenvolve o conceito de discurso social a fim de abordar os discursos como fatos sociais, e, em decorrência, também como fatos históricos. Por meio das manifestações individuais, e para além delas, procura observar as forças sociais identificadas com as regularidades, com as previsibilidades em determinado contexto. Nas palavras do autor, "a função mais importante dos discursos sociais, relacionada com o seu monopólio da representação, é produzir e consolidar legitimidades, validações, publicidades (no sentido de tornar públicos gostos, opiniões e informações)" (ibid., p. 65, tradução nossa).

A noção de discurso social se associa diretamente aos discursos hegemônicos que, por sua predominância e recorrência em dado momento histórico, afirmam sua legitimidade e a transferem para práticas sociais e visões de mundo: "os discursos sociais, para além da multiplicidade de suas funções, constroem o mundo social, o objetivam e, ao permitir comunicar essas representações, determinam essa boa convivência linguística que é o fator essencial da coesão social" (ibid., p. 67, tradução nossa). Dessa forma, o discurso social representa a sociedade como unidade, como um todo visível, por meio de "dispositivos de integração" (ibid., p.71, tradução nossa).

A proposta de Angenot, de uma crítica do discurso social, envolve a descrição "dos habitus de produção e de consumo" (ibid., p. 75, tradução nossa) vinculados a discursos e temas que constroem o mundo social, que promovem uma imagem de coesão social para determinada época. Essa abordagem discursiva inclui a identificação das representações de tipos sociais, produtores e destinatários, ou seja, da interação social colocada em jogo pela visão de mundo hegemônica, o que envolve noções como "aceitabilidade", "competências" (de produção e decodificação), "crença" e "encantamento" dos discursos (ibid., p. 76).

Em síntese: analisar o discurso social é considerar, no sentido do dialogismo bakhtiniano, a forma como texto e contexto se conjugam, e na forma como encenam a interação entre sujeitos, o que implica na afetação mútua. O discurso social, como construção de um mundo, projeta-o como ideal.

Tendo como perspectiva as questões levantadas por Fairclough e Angenot, procuramos compreender em que medida o discurso sobre o empreendedorismo social corresponde ao novo espírito do capitalismo (BOLTANSKI; CHIAPELLO, 2009). A base da discussão dessa teoria é a observação das manifestações discursivas de dada época, a fim de perceber como o capitalismo renova sua retórica e se ressignifica através dos tempos.

A partir dos paradigmas do mundo do trabalho, que alimentam o imaginário social, os autores verificam como a retórica do capital é capaz de produzir engajamento, 
de edificar códigos hegemônicos capazes de seduzir, de estimular as novas gerações a tomar parte, a assumir papéis nos processos capitalistas. A motivação não se resume a benefícios individuais, deriva principalmente de aspectos transcendentes, associados ao bem comum: dessa forma, o espírito do capitalismo é definido como "a ideologia que justifica o engajamento no capitalismo" (ibid., p. 39).

\title{
Novo espírito do capitalismo e empreendedorismo social
}

A retroalimentação do discurso do capital se dá, dentre outros fatores, pela assimilação das críticas formuladas por seus opositores, em reformulações que se concretizam para as gerações seguintes. O papel da crítica é apontar as lacunas, as brechas do capitalismo; a resposta é a reelaboração de um discurso que incorpora e desloca o discurso opositor, que resulta em um conjunto de crenças ajustado aos novos tempos, uma ideologia dominante:

\begin{abstract}
O espírito do capitalismo é justamente o conjunto de crenças associadas à ordem capitalista que contribuem para justificar e sustentar essa ordem, legitimando os modos de ação e as disposições coerentes com ela. Essas justificações, sejam elas gerais ou práticas, locais ou globais, expressas em termos de virtude ou em termos de justiça, dão respaldo ao cumprimento de tarefas mais ou menos penosas e, de modo mais geral, à adesão a um estilo de vida, em sentido favorável à ordem capitalista. (Ibid., 2009, p. 42).
\end{abstract}

No apontamento dos elementos que caracterizam o espírito do capitalismo, percebemos a proximidade das questões norteadoras dessa teoria com a tese do discurso social de Angenot. Ambas observam os discursos hegemônicos, legitimadores de modos de ser e pensar, de práticas sociais, de papéis a serem assumidos na ordem vigente. As organizações sociais têm papel-chave nesses processos, uma vez que, "submetidas ao imperativo da justificação, tendem a incorporar a referência a um tipo de convenção muito geral, orientada para um bem comum, com pretensão a validade universal" (ibid., p. 55).

Se Angenot faz derivar das falas individuais, dos textos de determinada cultura, a lógica da construção de um mundo social, ou seja, um discurso universalizante que promove a coesão social, Boltanski e Chiapello trilham o mesmo caminho para identificar o espírito do capitalismo, por meio das recorrências da visão de mundo, das práticas e dos ideais correspondentes a esse espírito. Nesse movimento, procuram apreender os princípios orientados à questão da justiça, do bem comum, através da análise das lógicas de justificação, mobilizadas para a produção do discurso responsivo ante as demandas sociais e o enfrentamento crítico dos opositores ao capitalismo.

Boltanski e Thévenot (1991, apud HERVIEUX; GEDAJLOVIC; TURCOTTE, 2010, p. 40) elencam seis lógicas de justificação, utilizadas como estratégias discursivas 
pelos atores sociais em situações de conflito ou controvérsia, a saber: inspirada - a lógica da criatividade; doméstica - a lógica da tradição; fama - a lógica da opinião; cívica a lógica do bem comum; industrial - a lógica da eficiência; mercado - a lógica da competição e do individualismo. Interessa-nos, no que tange ao discurso do empreendedorismo social, perceber como sua definição se organiza em torno da combinatória de lógicas distintas, e quais sentidos e paradoxos emergem do amálgama dessa articulação retórica.

No que o empreendedorismo social guarda relação com as questões relativas ao discurso social (ANGENOT, 2010) e ao espírito do capitalismo (BOLTANSKI; CHIAPELLO, 2009)?

Partimos do entendimento do empreendedorismo como correspondente ao espírito do capitalismo contemporâneo, discurso que está no cerne das teses de Drucker (2011), quando discute a sua visão da "sociedade empreendedora", como um possível "importante ponto crucial na história" (ibid., p. 364), uma espécie de revolução "sem derramamento de sangue, guerra civil, ou campos de concentração, sem catástrofe econômica, deliberadamente, com direcionamento, e sob controle" (ibid., p. 349).

Ehrenberg defende que, em nosso tempo, o empreendedor assume o caráter heroico, em diálogo com a visão de Baudelaire quando trata da constituição dos heróis na vida moderna - as figuras díspares da sociedade em processo de massificação: "o operário da fábrica, assim como o dândi, (...) o vagabundo, o desocupado ou o habitante de rua são, para Baudelaire, a expressão da modernidade: todos estão forçados a ter de realizar uma proeza que os fazem grandes e pela qual são os heróis da vida moderna" (EHRENBERG, 2010, p. 12). Na atualização dessa perspectiva baudelaireana, Ehrenberg conclui que "o empreendedor foi erigido como modelo da vida heroica porque ele resume um estilo de vida que põe no comando a tomada de riscos numa sociedade que faz da concorrência interindividual uma justa competição" (ibid., p. 13).

Diante desse cenário em que o empreendedor assume o espírito do capitalismo com traços heroicos, Dey e Steyaert (2010, p. 88) destacam o empreendedor social como um ator recente, associado a enunciados que ressaltam sua visão utópica e compõem uma grande narrativa, pautada pela ideia de mudança como um processo harmônico, inserida em um roteiro messiânico.

A similaridade entre empreendedor e empreendedor social, obviamente, é estabelecida pelo modus operandi comum a esses dois agentes, habilitados e engajados no uso das técnicas e tecnologias advindas do mercado para atingirem seus objetivos. A distinção entre ambos seria baseada no objetivo de suas ações: enquanto o empreendedor, em tese, prioriza o lucro, o ganho individual e os interesses de sua organização, o empreendedor social tem como meta a resolução de problemas sociais.

Nesse sentido, se o empreendedor comporta o caráter heroico, o empreendedor social alia os atributos do empreendedor com o termo social, a revestir suas ações com a aura do bem comum, como apontam Boltanski e Chiapello (2009). Forjado nos quadros do capitalismo neoliberal, ou formado tecnicamente para atuar em seus processos, 
o empreendedor social seria um subversor do capitalismo, um revolucionário que, no entanto, não abala os princípios do sistema que o concebe. Por vezes, é utilizado como suporte ao discurso legitimador do capital - quando, por exemplo, grandes corporações fazem aportes financeiros a empreendimentos sociais e investem significativamente em ações publicitárias para reverter esse apoio em imagem de marca, visando ao lucro.

Nesse sentido, o empreendedor social, a nosso ver, incorpora contemporaneamente o espírito do capitalismo, com vantagens simbólicas em relação à figura do empreendedor, por portar, em sua dimensão narrativa, a lógica do trabalho pela justiça social e a ação com vistas a "mudar o mundo".

\section{Papel social, mundos possíveis e utopia}

Dahrendorf, em sua teoria do homo sociologicus, desenvolve os conceitos de posição e papel social, em diálogo com a noção de theatrum mundi, do cenário social como palco da ação humana. Nessa tradição do pensamento, que remonta a Platão e passa por outros autores como Goffman, a metáfora do teatro vincula termos como "papel, parte, persona, personagem e máscara" (DAHRENDORF, 2012, p. 24; grifos do autor), correspondentes às "dramatis personae ou personagens da peça, cuja parte ou papel o ator desempenha" (ibid.).

O autor procura ultrapassar esse uso da metáfora teatral, ao observar a limitação dessa concepção, uma vez que, por trás do papel, da máscara, da entrada em cena, "o ator continua a ser um ser real, uma pessoa de modo nenhum afetada pelas partes que desempenha" (ibid., p. 24-25). Como contraponto, propõe "um uso mais manejável da metáfora teatral: a sua aplicação à vida do indivíduo, no sentido de atribuir a uma pessoa vários papéis ou personas" (p. 26).

A teoria de Dahrendorf define a posição como um lugar estabelecido em uma hierarquia social, a partir do qual são exigidos do sujeito certos modos de comportamento, determinadas atribuições e funções e a adoção de características específicas, aliando competências e aspectos morais. O papel, por sua vez, é pautado pela imagem construída em relação a essa posição; a leitura dos significados de um papel social é dada pela cultura, pelo ambiente sócio-histórico que o abriga. Dessa maneira, "a cada posição social pertence um papel social. Ao assumir uma posição social, o indivíduo torna-se uma personagem da peça escrita pela sociedade em que vive" (ibid., p. 37). Na combinatória entre os dois conceitos se estabelece a relação entre indivíduo e a sociedade, entre as atribuições de um sujeito e as grandes narrativas que alimentam o imaginário em torno de sua atividade, ou seja, o seu papel social.

Na direção apontada por Dahrendorf, analisamos o papel do empreendedor social na perspectiva de um discurso social que não somente versa sobre as suas características 
heroicas, de resiliência, de vocação para o bem comum, entre outras atribuições extraordinárias. Esse discurso também convoca os seus interlocutores - a alteridade projetada pelos contratos comunicativos (CHARAUDEAU, 2007), por meio de pacotes biopolíticos (PRADO, 2012) -, para tomar parte de um cenário construído em torno das práticas sociais representadas.

Trabalhamos com a hipótese de que os discursos sobre o empreendedorismo social, ajustados ao novo espírito do capitalismo, valem-se desse papel social para elaborar a construção de um mundo representado por práticas sociais modelares, que significam modos de engajamento para os consumidores midiáticos desses discursos. Por meio de narrativas exemplares, de biografias heroicas de empreendedores sociais, são elaborados mundos possíveis, direções futuras para uma sociedade pautada pela lógica capitalista, em registro retórico renovado.

Lazzarato (2006, p. 150) discute o capitalismo como "produção de modos de vida, como captura da proliferação de mundos possíveis", para concluir que "a empresa que produz um serviço ou uma mercadoria cria um mundo" (ibid., p. 99), no qual trabalhadores e consumidores devem se inserir de corpo e alma. Baseia-se na teoria de Gabriel Tarde para propor a noção de neomonadologia aplicada ao capitalismo contemporâneo. A ação da mônada se realiza sobre "as crenças e sobre os desejos, sobre as vontades e inteligências, ou seja, agir sobre os afetos" (ibid., p. 32), o que significa dizer que os mundos possíveis são constituídos por uma lógica de cooperação da ordem do sensível.

Interessa-nos compreender a noção de mundos possíveis através dos diagnósticos do presente e projeções do futuro, nos quais o empreendedor social assume o protagonismo de um processo de mudança social, construído narrativamente pelos discursos dos agentes que falam em nome de seu campo de atuação. Temos, dessa forma, a produção de uma comunidade imaginada (ANDERSON, 2005), pautada pelo espírito da transformação, pelo caráter de contornos revolucionários, incorporados à retórica que conjuga o capitalismo com uma visão utópica, por mais paradoxal que possa parecer essa combinação. Nesse aspecto, encontramos contemporaneamente o movimento de deslizamentos de sentido apontado por Boltanski e Chiapello (2009, p. 199), tendo como exemplo um momento fundamental de crítica ao capitalismo, na história social recente:

Os conflitos que marcam o ano 1968 em todo o mundo são expressão de uma elevação muito importante do nível de crítica às sociedades ocidentais. As formas de organização capitalista e o funcionamento das empresas, em especial, são o alvo dos contestadores, e, (...) essa crítica não é apenas verbal, mas vem acompanhada por ações que, em proporção nada desprezível, provocam a desorganização da produção. 
A geração de maio de 1968 marcou época por ambicionar outro mundo possível ${ }^{3}$, por se opor às instituições estabelecidas, por pregar lemas como "é proibido proibir". Esse enfrentamento crítico do capitalismo, passadas algumas gerações, é incorporado em seu espírito libertário e utópico ao engajamento na atividade do empreendedorismo social. Como podemos verificar no discurso do Skoll World Forum, organizado pela Skoll Foundation, uma das principais organizações globais de incentivo à cena empreendedora social:

Os empreendedores sociais são agentes de mudança da sociedade, criadores de inovações que perturbam o status quo e transformam o nosso mundo. Ao identificar as pessoas e os programas que já apresentam mudanças positivas, nós os capacitamos ["empower them", no original] a estender seu alcance, aprofundar o seu impacto e, fundamentalmente, melhorar a sociedade. (SKOLL WORLD FORUM, s/d.; tradução nossa).

No discurso do Skoll World Forum, encontramos o caráter revolucionário atribuído ao papel do empreendedor social, com destaque para as ações de "perturbar o status quo e transformar o mundo". De forma paradoxal, a visão utópica e revolucionária é acoplada à construção de um lugar de liderança, que é atribuído ao próprio enunciador, a Skoll Foundation. Ao promover o agenciamento da cena empreendedora social, a organização se posiciona como totalidade, como mundo possível no qual o poder do empreendedor social é amplificado. O diálogo intertextual entre a lógica contracultural da geração de maio de 68 e os significados do papel do empreendedor social resultam no processo de incorporação e deslocamento pelo discurso.

Esse processo se alinha à questão apontada nas análises de Dey e Steyaert (2010, p. 86): a construção narrativa do empreendedor social, por vezes, transmite a impressão de um ator social reificado, destituído de antecedentes históricos. Em outros momentos, há uma produção discursiva da historicidade do campo, ao se eleger personagens históricos com antecessores legítimos do que viria a ser, no futuro, esse ator social, como podemos perceber no discurso do Instituto de Empreendedorismo Social - IES, uma das principais organizações portuguesas do setor:

Sempre existiram empreendedores sociais ao longo da história, ainda que não o fossem assim designados. Alguns exemplos de empreendedores sociais:

- Florence Nightingale de Inglaterra, fundadora da primeira escola de enfermagem e desenvolvimento de práticas de enfermagem modernas na Segunda Guerra Mundial;

- Michael Young, fundador da "School for Social Entrepreneurs" (SSE), que desempenhou um papel central na promoção e legitimação do campo do empreendedorismo social. (IES, s/d.).

3 Um exemplo desse desejo revolucionário é a frase emblemática de um dos cartazes mais conhecidos, produzido no contexto das manifestações de maio de 1968: "Um lugar para todos em um mundo novo" (tradução nossa). Bibliothèque Nationale de France. Disponível em: <gallica.bnf.fr>. Acesso: 7 fev. 2014. 
Entre os precursores do empreendedorismo social, são apontados vários outros personagens históricos, como Maria de Montessori (1870-1952), nascida na Itália, educadora, médica, feminista, católica, reconhecida principalmente pelo desenvolvimento de um método educacional voltado às crianças, ou Madre Teresa de Calcutá (1910-1997), missionária nascida no Império Otomano, naturalizada indiana, fundadora da Ordem das Missionárias da Caridade, que foi beatificada pela Igreja Católica em 2003.

Ambas representam uma vertente tradicional, as ações de caridade e de apoio comunitário ${ }^{4}$, vinculadas a ordens religiosas, em ação desde o século XIX ante a emergência da "questão social", dos problemas que atingem os trabalhadores e os marginalizados da ordem capitalista em expansão (QUINTÃO, 2012). Em alguns discursos dessa cena, fica evidente a significação mítica do empreendedor social, representado pela imagem dos personagens históricos como os apontados acima. Entre os personagens contemporâneos, também alçados a essa dimensão mítica, destaca-se o economista bengalês Muhammad Yunus, vencedor do Prêmio Nobel, em 2006, por sua atuação à frente do Grameen Bank (Banco da Aldeia), um dos precursores da política de microcrédito aplicada ao combate à pobreza (YUNUS CENTRE, s/d.).

Como apontamos acima, a historicidade é uma construção discursiva; nesse sentido, encontramos nos textos sobre o empreendedor social um campo fértil para compreender esse processo de produção simbólica. Esse agente emerge da combinatória da vertente social, associada ao trabalho devoto pelo bem comum, com a mítica do empreendedor figura também de longo percurso histórico, emblemático para a lógica liberal capitalista.

Os paradoxos derivados desse encontro transparecem no trecho de citação ${ }^{5}$ destacada em publicação da Schwab Foundation, organização parceria do World Economic Forum: "os historiadores da economia do futuro vão olhar para esta geração de líderes e serem gratos. Eles assumiram o risco e transformaram o modelo vigente. Eles ajudaram a criar um mundo que enriqueceu a muitos e não apenas a alguns" (SCHWAB FOUNDATION, 2013, p. 5; tradução nossa).

Dessa junção surge a noção de visionário pragmático adotada pela Schwab; sua visão da transformação social é uma espécie de "multiplicação da riqueza", que atenderia a muitos - mas não a todos, deixando implícita a manutenção das desigualdades. A organização apresenta as características do empreendedor social sob sua ótica, traduzidas por critérios para identificação e reconhecimento de agentes pelo mundo afora, que recebem seu aval de qualidade e são tornados visíveis em sua plataforma digital e em seus eventos. Em síntese: "A Fundação Schwab emprega os seguintes critérios quando procura pelos principais empreendedores sociais: inovação, sustentabilidade, alcance e impacto social" (SCHWAB FOUNDATION, s/d.; tradução nossa).

4 Inclui-se, nesse espectro, a Santa Casa de Misericórdia de Lisboa - entidade tratada, a seguir, a partir de sua iniciativa chamada Banco de Inovação Social.

5 Fala atribuída a Nick O'Donohoe, CEO ("chief executive officer" ou diretor-executivo, em tradução livre) do instituto financeiro independente Big Society Capital (Reino Unido) e "vice chair" (vice-presidente, também em tradução livre) do Global Agenda Council on Social Innovation. 
No discurso da Schwab, estão as marcas intertextuais da presença do discurso mercadológico, do culto à performance, do espírito do capitalismo aplicado às lacunas deixadas pela falência, inoperância ou inexistência do Estado social. Termos advindos dos processos capitalistas, da gestão corporativa, por meio dos quais se estabelece uma espécie de herói contemporâneo. Um sujeito que agrega tanto a eficácia das técnicas e tecnologias do capitalismo, quanto uma formulação de utopia pragmática, um sonho materializado, concreto, um outro lugar que decorre, na verdade, da sustentabilidade exigida para a realização desse sonho.

Segundo Ehrenberg (2010, p. 13),

\begin{abstract}
Numa relação com o futuro caracterizada pela incerteza, que vê recuar, em nome da mudança permanente, a crença no progresso linear que simbolizava o Estado-providência, a ação de empreender é eleita como o instrumento de um heroísmo generalizado. É por isso que o sucesso empreendedor é considerado como a vida real do sucesso.
\end{abstract}

Nesse contexto, ao tratar do seu conceito de empreendedor social, o seu changemaker, a Ashoka acaba por elaborar a legitimação e mitificação do empreendedor. O empreendedor aparece em seu discurso como o verdadeiro herói a ser reverenciado por contribuir com a expertise mercadológica associada ao bem comum: "ao longo das últimas duas décadas, o setor cidadão descobriu o que o setor empresarial aprendeu há muito tempo: não há nada tão poderoso como uma ideia nova nas mãos de um empreendedor de primeira classe" (ASHOKA, s/d.; tradução nossa).

Na posição de uma das principais organizações mundiais do campo, autointitulada "pioneira no campo da inovação social", criada na Índia, em 1980, pelo norte-americano Bill Drayton, fica inscrita, com nitidez, a supremacia do mercado sobre a utopia transformadora. A sociedade empreendedora sonhada por Drucker, em sua expressão mais contundente.

\title{
Considerações finais
}

O estabelecimento da lógica empreendedora como paradigma do espírito do capitalismo, configurada como discurso social, é relativamente recente em termos históricos. Mais recente ainda é a visibilidade adquirida pelo empreendedorismo social. Por mais que se discuta a sua capacidade efetiva de influenciar decisivamente a economia dos países, de assumir para si a responsabilidade de substituir o Estado do bem-estar social, ou Estado-providência, há crescente recorrência, nesse momento histórico, dos discursos que projetam cenários de futuro capitaneados pelos empreendedores sociais.

O gesto de Cavaco Silva, presidente português, que dedicou o dia 12 de dezembro de 2013 ao empreendedorismo social ${ }^{6}$, é emblemático da aposta dos governantes nesses

6 Conforme reportagem intitulada "Cavaco Silva dedica o dia ao empreendedorismo social", publicada no site do Jornal Diário de Notícias, seção DN Política, em 12 dez. 2013. Disponível em: < http://www.dn.pt/politica/ interior.aspx?content_id=3583657> . Acesso em: 9 mar. 2014. 
atores sociais e na iniciativa da sociedade civil, em contexto de crise da economia, da representação política, entre outros desdobramentos do momento vivido pela sociedade portuguesa, representativa dos problemas recentes enfrentados no interior da União Europeia.

Na observação dos discursos regionais, encontramos consonâncias e choques com o discurso globalizado que constrói o papel do empreendedor social como um herói de nosso tempo, capaz de operar com os métodos, técnicas e tecnologias do capitalismo, e simultaneamente revolucioná-lo, "perturbar o status quo", como defende o discurso da Skoll Foundation. Vejamos a mensagem divulgada na página do Facebook do BIS - Banco de Inovação Social, entidade lançada em 30 de abril de 2013, que reproduz a leitura crítica da Comissão Europeia a respeito da inovação social, no âmbito do Programa Europa 2020:

O futuro Programa da União Europeia para a Mudança e Inovação Social (2014-2020) parte do seguinte pressuposto: “A inovação social, e em especial a experimentação social, pode ser uma ferramenta poderosa para configurar as reformas e as adaptações políticas necessárias à aplicação da estratégia Europa 2020.

Não obstante, o desenvolvimento e a disseminação, a uma escala mais vasta, de uma abordagem de inovação social na União são prejudicados por vários factores, designadamente:

- a fragmentação de esforços e recursos, a falta de transparência e visibilidade, apoios financeiros limitados e a insuficiência de competências técnicas capazes de ajudar as organizações a desenvolver e gerar inovações sociais". (BIS, 2013).

O BIS, iniciativa da Santa Casa de Misericórdia de Lisboa, historicamente vinculada às caridades e ao voluntariado tradicional, é a tradução da tradicional entidade ao campo do empreendedorismo e inovação social. Sua estratégia é se posicionar como interlocutora, mediadora e reguladora nas relações entre a Comissão Europeia e suas formas de incentivo, e a cena empreendedora social portuguesa. Assume, assim, o objetivo de "catalisar todos os recursos financeiros possíveis" para agenciar sua distribuição aos projetos da sociedade civil portuguesa.

Talvez involuntariamente, ao tentar demarcar seu espaço legítimo de intervenção, acaba por assumir a voz da desconstrução do discurso messiânico, utópico e revolucionário associado ao papel do empreendedor social. Essa fissura na grande narrativa do empreendedorismo social oferece pistas para compreender como esse agente, por maior que seja seu compromisso com o bem comum, pode possuir limitações, falhas e zonas obscuras em sua atuação. Além disso, também traz à tona a disputa de poder por organizações que assumem posições de liderança, elaboram mundos possíveis para os quais somos convocados a participar, seja como empreendedores sociais, seja como voluntários engajados nesses projetos.

Por meio da análise dos discursos sobre o empreendedorismo social, temos acesso ao imaginário que abastece um processo de mudança, na reconfiguração da retórica 
do capital para novos tempos - para os quais, apesar dos mundos possíveis apresentados em tom eufórico, somente temos incertezas. O olhar para o futuro, antes de ser premonitório, é revelador do que está em jogo em dado cenário social.

Vander Casaqui é professor do Programa de Pós-Graduação em Comunicação e Práticas de Consumo - ESPM. Doutor em Ciências da Comunicação pela Universidade de São Paulo, com pós-doutorado pela FCSH - Universidade Nova de Lisboa.

vander.casaqui@gmail.com.br

\section{Referências}

ANDERSON, B. Comunidades imaginadas: reflexões sobre a origem e a expansão do nacionalismo. Lisboa: Edições 70, 2005.

ANGENOT, M. El discurso social: los limites históricos de lo pensable y lo decible. Buenos Aires: Siglo XXI, 2010.

ASHOKA. What is a social entrepreneur?, s.d. Disponível em: <https://www.ashoka.org/social_ entrepreneur>. Acesso em: 12 mar. 2014.

BIS - Banco de Inovação Social. Mensagem no perfil do Facebook da organização. Publicada em: 23 abr. 2013. Disponível em: <https://www.facebook.com/bancodeinovacaosocial.pt?fref=ts $>$. Acesso em: 9 mar. 2014.

BOLTANSKI, L.; CHIAPELLO, È. O novo espírito do capitalismo. São Paulo: Martins Fontes, 2009.

BOURDIEU, P. O poder simbólico. Rio de Janeiro: Bertrand, 2009.

CHARAUDEAU, P. Discurso das mídias. São Paulo: Contexto, 2007.

DAHRENDORF, R. Homo sociologicus. Lisboa: Quetzal, 2012.

DEY, P.; STEYAERT, C. The politics of narrating social entrepreneurship. Journal of Enterprising Communities - people and places in the global economy, 4 (1), p. 85-108, 2010.

DRUCKER, P. F. Inovação e espírito empreendedor: prática e princípios. São Paulo: Cengage Learning, 2011.

EHRENBERG, A. O culto da performance: da aventura empreendedora à depressão nervosa. Aparecida: Idéias \& Letras, 2010.

FAIRCLOUGH, N. Discurso e mudança social. Brasília: Ed.UNB, 2001.

HERVIEUX, C.; GEDAJLOVIC, E.; TURCOTTE, M-F. B. Legitimization of social entrepreneurship. Journal of Enterprising Communities: people and places in the global economy, 4(1), p. 37-67, 2010.

IES - Instituto de Empreendedorismo Social. O que é Empreendedorismo Social?, s/d. Disponível em: $<$ http://www.ies.org.pt/conhecimento/o_que_e_empreendedorismo_social/>. Acesso em: 8 mar. 2014. 
LAZZARATO, M. As revoluções do capitalismo. Rio de Janeiro: Civilização Brasileira, 2006.

PRADO, J. L. A. Política da imagem na era da convocação. Significação: Revista de Cultura Audiovisual, 39 (37), p. 167-187, 2012.

QUINTÃO, C. A reemergência do Terceiro Setor. In: VELOSO, L.; CARMO, R. M. (orgs.). A constituição social da economia. Lisboa: Mundos Sociais, 2012, p. 123-153.

SCHWAB FOUNDATION. Breaking the binary: policy guide to scaling social innovation. Schwab, 2013. Disponível em: <http://www.schwabfound.org/content/publications >. Acesso em: 10 mar. 2014.

SCHWAB FOUNDATION. What is a Social Entrepreneur?, s/d. Disponível em: <http://www. schwabfound.org/content/what-social-entrepreneur>. Acesso em: 10 mar. 2014.

SKOLL WORLD FORUM. What is social entrepreneurship?, s/d. Disponível em: <http:// skollworldforum.org/about/what-is-social-entrepreneurship/>. Acesso em: 10 mar. 2014.

YUNUS CENTRE. s/d. Disponível em: <http://www.muhammadyunus.org/>. Acesso em: 9 mar. 2014.

Artigo recebido em julho e aprovado em novembro de 2014. 